\title{
Mediastinal Mass in a Brain Tumor Patient Treated with Chemotherapy: Lymphoma after Temozolomide
}

\author{
Austin Dixon, MD, MBA*, Bennett Chin, MD, Matthew McKinney, MD \\ Duke University Hospital, Durham, NC 27710
}

${ }^{\star}$ Corresponding author: Austin Dixon, MD, MBA, Duke University Hospital, Durham, NC 27710; Tel: (919)684-7289; Fax: (919)684-715; Email: austin.x.dixon@duke.edu

Received: March 28, 2019; Accepted: April 04, 2019; Published: April 20, 2019;

\begin{abstract}
Patients with brain tumors are frequently treated with combination chemotherapy and radiation therapy. Alkylating agents, such as Temozolomide, have known carcinogenic effects and are associated with secondary malignancies. This case illustrates the FDG PET / CT findings of an astrocytoma patient treated with Temozolomide presenting with an unknown mediastinal mass, with lymphoma being the most likely diagnosis.
\end{abstract}

Keywords: Temozolomide, brain tumor, astrocytoma, secondary malignancy, Fluorodeoxyglucose (FDG) PET / CT, lymphoma

\section{Case Report}

Figure 1. A 41-year-old male with a history of brain tumor and prior chemotherapy presented with numerous symptoms including back pain. He underwent tumor resection resulting in a pathologic diagnosis of transformed astrocytoma and also received Temozolomide therapy $\left(50 \mathrm{mg} / \mathrm{m}^{2}\right)$ over approximately 4 years. Upon presentation, an MRI revealed leptomeningeal spread, and additionally, a posterior mediastinal mass. Subsequently, a PET/CT was obtained following intravenous administration of $14.2 \mathrm{mCi}$ of fluorine-18 fluorodeoxyglucose (18F-FDG). This study demonstrated intense uptake in the mediastinal mass (Figure 1; A-transaxial CT; B- transaxial FDG PET; C-transaxial fused PET / CT; D-maximum intensity projection FDG PET).

Biopsy confirmed lymphoid malignancy suspicious for Hodgkin's disease. Brain tumor therapies with radiation and Temozolomide have demonstrated clinical efficacy [1]. The differential diagnosis for a secondary malignancy in patients with brain malignancies treated with Temozolomide includes hematologic malignancies, however, the only solid malignancy previously reported is lymphoma [2-10]. A recent literature review demonstrated 5 reported cases of lymphoma [7]. All of the other 12 patients either had myelodysplasia or aplastic anemia [7].

Metastatic disease from primary brain tumors outside of the nervous system is extremely uncommon occurring in $<2 \%$ of the cases; this is attributed to physical barriers including the dura mater and the thickened basement membrane of the blood vessels [11]. In the clinical context of a brain tumor previously treated with Temozolomide, and a suspected extracranial malignant tumor by FDG PET / CT, lymphoma is the primary diagnostic consideration.

\section{REFERENCES}

1. Stupp R, Taillibert S, Kanner AA, Kesari S, Steinberg DM, Toms SA, Taylor LP, Lieberman F, Silvani A, Fink KL, Barnett GH, Zhu JJ, Henson JW, Engelhard HH, Chen TC, Tran DD, Sroubek J, Tran ND, Hottinger AF, Landolfi J, Desai R, Caroli M, Kew Y, Honnorat J, Idbaih A, Kirson ED, Weinberg U, Palti Y, Hegi ME, Ram Z. Maintenance therapy with tumor- treating fields plus temozolomide vs temozolomide alone for glioblastoma: A randomized clinical trial. Jama. 2015; 314: $2535-2543$

2. Karremann M, Kramer N, Hoffmann M, Wiese M, Beilken A, Corbacioglu S, Dilloo D, Driever PH, Scheurlen W, Kulozik A, Gielen GH, von Bueren AO, Durken M, Kramm CM. Haematological malignancies following temozolomide treatment for paediatric high- grade glioma. European journal of cancer (Oxford, England : 1990). 2017; 81:1-8

3. Goyal S, Singh RR, Balukrishna S, Bindra M, Backianathan S. An early and rare second malignancy in a treated glioblastoma multiforme: Is it radiation or temozolomide? Journal of clinical and diagnostic research : JCDR. 2015; 9 ; Td05-07

4. Broes K, Van Ginderachter L, Joosens E, Maes A, Theunissen K, Schepers S, Deben $\mathrm{K}$, Claes J, Mebis J, Cox T. Secondary non-hodgkin lymphoma of the ethmoid sinus after temozolomide. B-ent. 2015; 11: 73-76

5. Van Ginderachter L, Cox T, Drijkoningen R, Achten R, Joosens E, Maes A, Theunissen K, Mebis J. Non-hodgkin lymphoma after treatment with extended dosing temozolomide and radiotherapy for a glioblastoma: A case report. Case reports in oncology. 2013; 6: 45- 49

6. Momota H, Narita Y, Miyakita Y, Shibui S. Secondary hematological malignancies associated with temozolomide in patients with glioma. Neuro-oncology. 2013; 15 1445- 1450

7. Clark SW, Taylor J, Wang DL, Abramson JS, Batchelor TT. Plasmablastic lymphoma after standard-dose temozolomide for newly diagnosed glioblastoma. Neurology. 2013; 81: 93- 94

8. Natelson EA, Pyatt D. Temozolomide-induced myelodysplasia. Advances in hematology. 2010; 2010: 760402

9. Sharma A, Gupta D, Mohanti BK, Thulkar S, Dwary A, Goyal S, Muzumder S, Das P. Non- hodgkin lymphoma following temozolomide. Pediatric blood \& cancer. 2009; 53: 661-662

10. Su Y-W, Chang M-C, Chiang M-F, Hsieh R-K. Treatment-related myelodysplastic syndrome after temozolomide for recurrent high-grade glioma. Journal of NeuroOncology. 2005; 71: 315-318

11. Ray A, Manjila S, Hdeib AM, Radhakrishnan A, Nock CJ, Cohen ML, Sloan AE. Extracranial metastasis of gliobastoma: Three illustrative cases and current review of the molecular pathology and management strategies. Molecular and clinical oncology. 2015; 3: 479-486 
Figure 1.

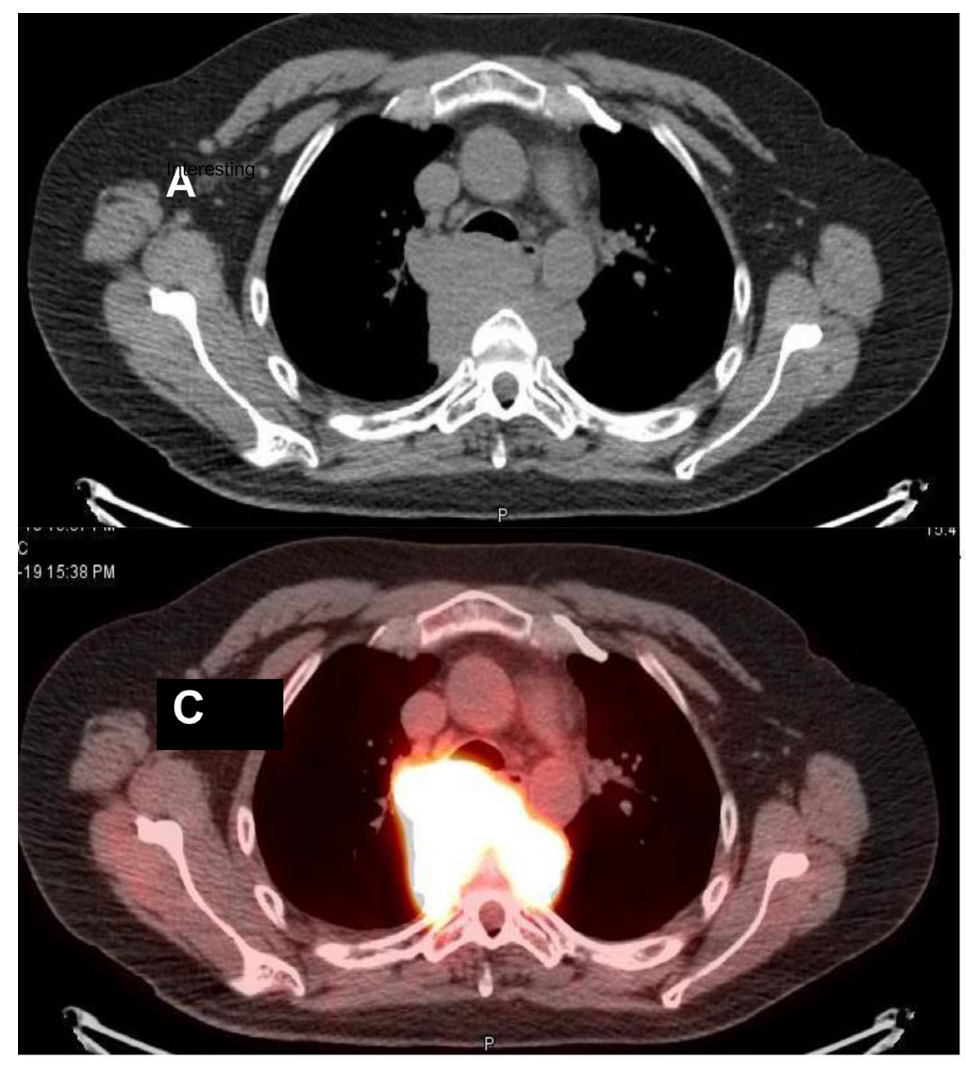

B

D

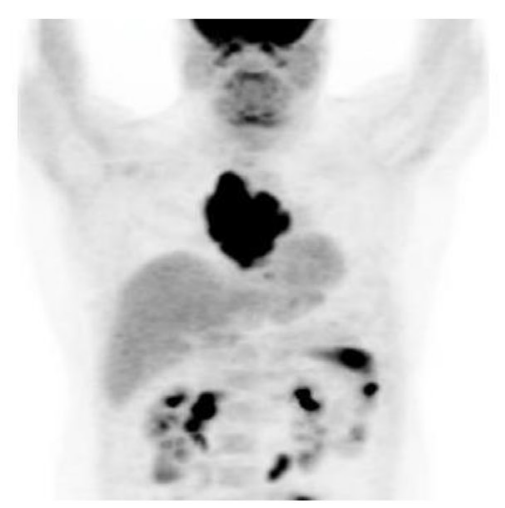

\section{Citation:}

Austin Dixon, Bennett Chin, Matthew McKinney (2019) Mediastinal Mass in a Brain Tumor Patient Treated with Chemotherapy: Lymphoma after Temozolomide. J Clin Res Med Volume 2(2): 1-2. 